\title{
Milk from different species: Relationship between protein fractions and inflammatory response in infants affected by generalized epilepsy
}

\author{
M. Albenzio, ${ }^{* 1}$ A. Santillo, ${ }^{*}$ M. G. Ciliberti, ${ }^{*}$ L. Figliola, ${ }^{*}$ M. Caroprese, ${ }^{*}$ R. Marino, ${ }^{*}$ and A. N. Polito† \\ *Department of the Sciences of Agriculture, Food and Environment (SAFE), University of Foggia, Via Napoli, 25, 71100 Foggia, Italy \\ †Complex Structure of Neuropsychiatry Childhood-Adolescence of Ospedali Riuniti of Foggia, Viale Pinto, 71100 Foggia, Italy
}

\begin{abstract}
The present study was undertaken to evaluate the effect of protein fractions from bovine, caprine, and ovine milk on production of cytokines and reactive oxygen species (ROS) and reactive nitrogen species (RNS) by cultured peripheral blood mononuclear cells (PMBC) from infants with generalized epilepsy. Bovine, caprine, and ovine bulk milks were pasteurized and analyzed for chemical composition. Then, PBMC were isolated from 10 patients with generalized epilepsy ( 5 males; mean age $33.6 \pm 5.4 \mathrm{mo})$. Production of tumor necrosis factor- $\alpha$ (TNF- $\alpha$ ), IL-10, IL-6, and IL-1 $\beta$ was studied in cultured PBMC (from infants with epilepsy and controls) stimulated by bovine, caprine, and ovine milk and casein and whey protein fractions, and levels of ROS and RNS were measured in the culture supernatant. The ability of PBMC to secrete cytokines in response to milk and protein fraction stimulation may predict the secretion of soluble factor TNF- $\alpha$ in the bloodstream of challenged patients. Bovine, caprine, and ovine bulk milks induced low-level production of IL-10 by cultured $\mathrm{PBMC}$ in at least $50 \%$ of cases; the same behavior was observed in both casein and whey protein fractions for all species studied. Bovine and ovine milk and their casein fractions induced production of lower levels of IL-1 $\beta$ in $80 \%$ of patients, whereas caprine milk and its casein fraction induced the highest levels in $80 \%$ of patients. The amount of IL-6 detected after stimulation of PBMC by milk and its fractions for all species was lower than that of other proinflammatory cytokines. In the bovine, total free radicals were higher in bulk milk and lower in the casein fraction, whereas the whey protein fraction showed an intermediate level; in caprine, ROS/RNS levels were not different among milk fractions, whereas ovine had higher levels for bulk milk and casein than the whey protein fraction. Lower levels of ROS/RNS detected in PBMC cultured with caprine
\end{abstract}

Received December 1, 2015.

Accepted March 4, 2016.

${ }^{1}$ Corresponding author: marzia.albenzio@unifg.it milk fraction could be responsible for the lower levels of TNF- $\alpha$ cytokine in the corresponding fraction. Cytokines might be useful biomarkers to discriminate the effects of foods on the inflammatory response; dietary strategies could help in alleviating the negative effects of epilepsy in infants.

Key words: milk source, cytokine, infant, peripheral blood mononuclear cells, reactive oxygen species

\section{INTRODUCTION}

Milk composition of the principal dairy species varies widely in terms of genetic, physiological, and nutritional factors, and environmental conditions. Milk protein is a very heterogeneous group of molecules mainly influenced by genetic variants (Ng-Kwai-Hang and Grosclaude, 2003). Genetic polymorphism varies among ruminant species and is associated with different level of protein synthesis in milk, different rates of phosphorylation and glycosylation of the peptide chain, and different AA sequences of the protein (Michaelidou, 2008).

Epilepsy comprises a group of neurological disorders characterized by the periodic occurrence of spontaneous seizures (Vezzani et al., 2008); the World Health Organization estimates that it affects $0.8 \%$ of the world's population (Li et al., 2011). Several reports suggest that certain foods might trigger seizures; studies using animal models reported a reduction in seizure threshold in rats administered excess dietary AA and the induction of convulsions by monosodium glutamate (Asadi-Pooya et al., 2008). Furthermore, in recent study, at least $30 \%$ of children with intractable epilepsy had intakes below the recommended dietary allowance for vitamins D, E, and K, folate, calcium, and linoleic acid (Volpe et al., 2007). Gordon and Dooley (2015) conducted a cross-sectional survey on food insecurity and health status and concluded that the experience of food insecurity appears to be more frequent among persons living with epilepsy.

In human newborns, milk fulfils nutritional needs and ensures safe development and growth during the first stages of life. Recently, the role of animal food 
products on diet has been widely recognized, with particular regard on the effects of protein fractions and human health. It is well known that milk proteins play an important role in the ability to stimulate innate immune response through the activation of pro- and antiinflammatory cytokines (Albenzio et al., 2012); these molecules rapidly increase in the peripheral blood. In recent years, an increasing body of evidence has indicated a complex relationship between epilepsy and the immune system (Li et al., 2011). Abnormalities in expression of cytokines and immune cells have been observed in patients with epilepsy and in animal models (Plata-Salamán et al., 2000; Ravizza and Vezzani, 2006). Oxidative stress is known to occur in the pathogenesis of the most prevalent form of epilepsy and contributes to acute injury-induced neuronal damage (Pearson et al., 2015).

To the best of our knowledge, no studies have been reported on the role of milk protein fractions from different ruminant species on immune status of infants with epilepsy. Therefore, the present study was undertaken to evaluate the effect of milk protein fractions from different animal species - bovine, ovine, and caprine - on production of pro- and antiinflammatory cytokines and reactive oxygen species by cultured peripheral blood mononuclear cells from infants with generalized epilepsy.

\section{MATERIALS AND METHODS}

\section{Experimental Design and Milk Sampling}

Pasteurized bovine, caprine, and ovine bulk milks were lyophilized (lyophilization cycle $-50^{\circ} \mathrm{C}$ for $24 \mathrm{~h}$; Lio5P, 5 Pascal s.r.l., Trezzano, Milan, Italy) and the resulting lyophilized powders stored at $4^{\circ} \mathrm{C}$. Bovine, caprine, and ovine milk samples were analyzed for chemical composition using an infrared spectrophotometer (Milko Scan 133B; Foss Electric, Hillerød, Denmark). Casein and whey protein fractions were obtained according to IDF (1993).

\section{Patients}

Ten patients with generalized epilepsy (5 males; mean age $33.6 \pm 5.4 \mathrm{mo}$ ) and 10 control (5 males; mean age $35.6 \pm 6.8 \mathrm{mo}$ ) were recruited at the Complex Structure of Neuropsychiatry Childhood- Adolescence of Ospedali Riuniti (Foggia, Italy) and were included in the study.

Inclusion criteria were diagnosis of active and unambiguous focal or generalized epilepsy according to International League Against Epilepsy (ILAE) criteria (Berg et al., 2010) with no family history of epilepsy without any other concomitant systemic, neurological, or psychiatric diseases and without any abnormalities on neuroradiological investigations.

Exclusion criteria were occurrence of clinical seizures within the last $3 \mathrm{~d}$ before blood drawing, malignant tumor, concomitant inflammatory disease, severe neurological or neuroimmunological disease (i.e., stroke, cerebral hemorrhage, encephalitis, meningitis), immunosuppressive or immunomodulatory treatment during the last 6 mo, surgery or significant trauma within the last $2 \mathrm{wk}$, hepatic or renal insufficiency, or severe psychiatric disease.

Approval was obtained from the Ospedali Riuniti (Foggia, Italy) Institutional Review Board for these studies. Written informed consent was obtained from the parents in accordance with the Declaration of Helsinki on the Ethical Principles for Medical Research Involving Human Subjects (http://www.wma.net/ en/30publications/10policies/b3/17c.pdf).

Production of tumor necrosis factor- $\alpha$ (TNF- $\alpha)$, IL10, IL-6, and IL-1 $\beta$ was studied in peripheral blood mononuclear cells (PBMC) stimulated with bovine, caprine, and ovine milk and casein and whey protein fractions. The PBMC were obtained from infants with generalized epilepsy and from control infants. The PBMC were isolated from heparinized blood $(3-5 \mathrm{~mL})$ by gradient centrifugation in Ficoll-Histopaque (Sigma Aldrich, Milan, Italy). The viability of PBMC was checked by measuring Trypan blue dye exclusion and was $>90 \%$. The PBMC were resuspended at a final concentration of $1.5 \times 10^{5}$ cells $/ \mathrm{mL}$ in RPMI 1640 (Sigma Aldrich) supplemented with L-glutamine, penicillin/streptomycin, and 10\% fetal bovine serum (Sigma Aldrich). The PBMC were distributed in $0.2 \mathrm{~mL}$ of calcium medium into flat-bottomed 96-well microtiter plates, cultivated for $5 \mathrm{~d}$ at $37^{\circ} \mathrm{C}$ in a $5 \% \mathrm{CO}_{2}$ incubator in the presence of bulk milk, casein, or whey protein obtained from bovine, caprine, and ovine species. After the 5-d incubation, PBMC viability was $>90 \%$. Concentration of the tested proteins used for stimulation was $100 \mu \mathrm{g} / \mathrm{mL}$. The PBMC were stimulated to determine production of inflammatory and proinflammatory cytokines with $50 \mu \mathrm{L}$ of phytohemagglutinin (PHA, final concentration $10 \mu \mathrm{g} / \mathrm{mL}$, Sigma Aldrich). The mitogen PHA $(10 \mu \mathrm{g} / \mathrm{mL})$ was used as positive control stimulus to ensure normal immune reactivity to control stimuli in the subjects, whereas cells not activated with mitogen represented negative controls. At the end of the incubation period, quadruplicate culture supernatants were harvested and stored at $-20^{\circ} \mathrm{C}$ until used in cytokine assays. Levels of TNF- $\alpha$, IL-10, IL- 6 , and IL-1 $\beta$ in the culture supernatants were determined in duplicate using commercial Luminex Multiplex Assays (Labospace, Milan, Italy); results were expressed in pi- 
cograms per milliliter. Briefly, the Bio-Plex Calibration kit (\#171203060, Labospace) and Bio-Plex Validation kit (\#171203001, Labospace) were used to prepare a standard curve for each cytokine. The analysis was performed using a BioRad Bio-Plex 100 with the magnetic luminex screening assay (BioRad, Milan, Italy).

The level of reactive oxygen species (ROS) and reactive nitrogen species (RNS) was measured in the culture supernatants using an OxiSelect in vitro ROS/ RNS Assay Kit (Cell Biolabs Inc., San Diego, CA) according to the manufacturer's instructions. Data were normalized to protein level (measured by BCA Protein Assay Kit, Thermo Scientific, Rockford, IL). The ROS/ RNS were expressed as $2^{\prime}, 7^{\prime}$-dichlorodihydrofluorescein $(\mathrm{DCF})$ in millimoles per liter $(\mathrm{m} M)$.

Cytokines and ROS/RNS levels in control patients did not show differences for milk species and protein fractions; mean values of TNF- $\alpha$, IL-10, IL- $1 \beta$, and IL-6 in bovine, ovine, and caprine milks were $150 \pm 55$, $25 \pm 3,45 \pm 18$, and $140 \pm 52 \mathrm{mg} / \mathrm{mL}$ of protein and values of ROS/RNS were $0.7 \pm 0.02,0.5 \pm 0.01$, and $0.4 \pm 0.03 \mathrm{~m} M$ in the 3 milks, respectively.

\section{Statistical Analysis}

All variables were tested for normal distribution using the Shapiro-Wilk test (Shapiro and Wilk, 1965). Data on cytokines and ROS/RNS were analyzed by ANOVA using the GLM procedure of SAS (SAS Institute, 2011). The tested parameters were always lower $(P<0.001)$ in controls than in infants with epilepsy; data on control infants were used as a baseline to evaluate the response of infants with epilepsy. The effects of milk source, milk protein fractions, and their interaction were tested within infants with epilepsy. For each cytokine, the levels in controls were used as a threshold level to group the response of infants with epilepsy into 3 levels (low, medium, and high), where low, medium, and high groups had increases $<30 \%$, from 30 to $70 \%$, and $>70 \%$ relative to the threshold level, respectively. The percentage of patients ascribed to each level is reported. When significant effects were found $(P<0.05)$, Student's $t$-test was used to identify significant differences between means.

\section{RESULTS AND DISCUSSION}

\section{Composition of Bovine, Caprine, and Ovine Milks}

Chemical composition of pasteurized bovine, caprine, and ovine milks is reported in Table 1. Milk composition from more represented dairy species is characterized by a great complexity of milk nutrients (Fox,
Table 1. Chemical composition of bovine, caprine, and ovine pasteurized milk (means \pm SEM)

\begin{tabular}{lccc}
\hline & \multicolumn{3}{c}{ Milk species } \\
\cline { 2 - 4 } Component & Bovine & Caprine & Ovine \\
\hline Protein, \% & $3.53 \pm 0.56$ & $3.22 \pm 0.35$ & $6.01 \pm 0.48$ \\
Casein, \% & $2.72 \pm 0.10$ & $2.29 \pm 0.12$ & $4.56 \pm 0.13$ \\
Whey protein, \% & $0.85 \pm 0.02$ & $0.96 \pm 0.01$ & $1.42 \pm 0.02$ \\
Fat, \% & $3.63 \pm 0.12$ & $4.14 \pm 0.15$ & $8.16 \pm 0.32$ \\
Lactose, \% & $4.69 \pm 0.10$ & $4.18 \pm 0.12$ & $4.37 \pm 0.11$ \\
\hline
\end{tabular}

2003). In this study, percentage composition of bovine and caprine milks was comparable for protein content and for casein and whey protein fractions. As expected, ovine milk exhibited a higher percentage of principal chemical components reported in Table 1; protein fractions in ovine milk were twice as high as those found in bovine and caprine milks. The percentage of fat content ranged from 3.63 to $8.16 \%$ from bovine to ovine milk; in caprine milk, fat content was $4.14 \%$. Among milk components, proteins are species-specific mainly due to genetic polymorphisms; in particular, the genetic polymorphisms of milk proteins from small ruminant species are of importance as they are associated with quantitative and qualitative parameters in milk (Albenzio and Santillo, 2011).

\section{Cytokines and ROS/RSN in Cultured PBMC}

Effects of milk protein fractions of bovine, caprine, and ovine milks on cytokine levels in cultured PBMC are presented in Table 2. Cytokines are generally synthesized and secreted in response to immunological stimuli; they are soluble, potent glycoproteins involved in the regulation of growth, immune cell activation, and inflammatory and immune responses able to travel to distant cells in other organs via the peripheral circulation (Youn, 2013). Tumor necrosis factor- $\alpha$ produced by PBMC cultured with bulk milk was lower $(P<0.05)$ for bovine and ovine milk in 80 and $70 \%$ of the infants respectively, whereas caprine milk induced higher levels of this cytokine in $80 \%$ of infants. However, the levels of TNF- $\alpha$ detected in PBMC stimulated with caprine milk reached lower levels $(P<0.05)$ than those against bovine and ovine milks. For the casein fraction, a higher percentage of patients ascribed to a lower production of TNF- $\alpha$ regardless of species. The whey protein fraction regardless of species was able to induce higher levels of TNF- $\alpha$ in 10\% of infants; in particular, this value was 4 -fold and 11 -fold higher $(P<0.01)$ in bovine and ovine than the level of TNF- $\alpha$ produced by PBMC cultured with the caprine whey protein fraction, respectively. Furthermore, TNF- $\alpha$ produced by PBMC 
cultured with bovine and ovine whey proteins was lowest in $70 \%$ of patients, whereas TNF- $\alpha$ produced by PBMC cultured with the caprine whey protein fraction showed intermediate levels in $80 \%$ of cases. The ability of PBMC to secrete cytokines in response to milk and protein fraction stimulation may be a predictor of the secretion of soluble factor TNF- $\alpha$ in the bloodstream of challenged patients. Several studies have reported that TNF- $\alpha$ might acts in a concentration-dependent manner; TNF- $\alpha$ has been shown to play a proconvulsive role in Shigella-mediated seizures at low concentration but exert an anticonvulsive effect at higher concentration (Yuhas et al., 2003). In the central nervous system, TNF- $\alpha$ can activate its 2 receptors, p55 and p75, and may modulate cell-signaling pathways: a low concentration of TNF- $\alpha$ may predominantly activate proconvulsive effects via p55, whereas a high concentration of TNF- $\alpha$ can play anticonvulsive role through the p75 pathway (Li et al., 2011).

Bovine, caprine, and ovine bulk milks induced lowlevel production of IL-10 by cultured PBMC in at least $50 \%$ of cases; the same behavior was observed in both casein and whey protein fractions for all milk species studied. In general, the total amount of IL-10 detected was lower than that of other cytokines involved in this study. Interleukin-10 has broad anti-inflammatory properties by its inhibition of antigen-presenting cell function and suppression of production of proinflammatory cytokines (O'Garra et al., 2008). Indeed, IL10 deactivates macrophages, which in turn decreases the production of cytokines by T cells (Youn, 2013). Several animal studies and clinical observations suggest an anticonvulsant effect of IL-10; one report showed protective effects of IL-10 against the development of epileptiform activity evoked by transient episodes of hypoxia in rat hippocampal slices (Levin and Godukhin, 2007). Production of IL-10 in blood is controversial; some authors reported no differences in plasma IL-10 between patients with focal seizure and control (Virta et al., 2002), whereas IL-10 production was significantly lower in patients suffering from focal seizure than in healthy control (Li et al., 2011). Youn (2013) reported that IL-10 was significantly elevated in plasma 48 to $72 \mathrm{~h}$ after seizure onset, leading to the hypothesis that IL-10 may have an anticonvulsive effect in neonatal seizure patients by suppressing proinflammatory cytokines production. In a previous study, Albenzio et al. (2012) found higher levels of IL-10 in PBMC cultured against bovine and caprine milk fractions in both healthy infants and in infants with cow milk allergy; in the current study, the lower level of IL-10 could be ascribed to the impaired immunological status of infants affected by generalized epilepsy.
Bovine milk and casein fraction induced the lowest levels $(P<0.01)$ of IL-1 $\beta$ from cultured PBMC in $80 \%$ of patients, whereas whey protein induced the highest level in $60 \%$ of cases. Caprine milk and casein fraction induced the highest levels $(P<0.01)$ of the same cytokine in $80 \%$ of cases and whey protein induced intermediate level in $80 \%$ of cases. Ovine milk induced medium levels of IL-1 $\beta$ in $60 \%$ of cases and low levels in $80 \%$ of cases for casein and whey protein fractions. The IL-1 family comprises 3 ligands, IL- $1 \alpha$, IL- $1 \beta$, and IL-1Ra; IL- $1 \beta$ is mostly secreted, whereas IL- $1 \alpha$ is predominantly membrane-bound. Interleukin-1 $\beta$ plays a role in promoting excite-toxicity and perhaps in seizure generation (Vezzani and Baram, 2007). A notable example of a dual role of cytokines on neuronal survival in diseased tissue exists; in particular, neuroprotective actions of IL-1 $\beta$ have been reported, likely mediated by its ability to induce the synthesis of the growth factors of astrocytes, promoting cell repair mechanisms. Other mechanisms of neuroprotection induced by cytokines include stimulation of antioxidant pathways; in this respect, IL- $1 \beta$ and TNF- $\alpha$ can either reduce or exacerbate glutamate receptor-mediated excite-toxicity depending on their extracellular concentrations, the length of time the tissue is exposed to these cytokines during injury, and the receptor time activated by this cytokines (Bernardino et al., 2005). Chronic expression of IL-1 $\beta$ during epileptogenesis highlights the possibility that this cytokine might be involved in the mechanisms underlying the onset of spontaneous seizures (Vezzani et al., 2008).

Caprine bulk milk showed the highest level $(P<0.01)$ of IL-6 in $80 \%$ of patients, bovine milk showed intermediate levels in $50 \%$ of patients, and ovine milk showed the lowest level in $60 \%$ of patients. Bovine and caprine casein fractions stimulated higher levels of IL-6 in $80 \%$ of cases, whereas ovine casein stimulated a lower level in $80 \%$ of cases. Apart from animal species, the whey protein fraction stimulated a lower IL-6 level in most of the studied patients. The complexity of the PBMC response against stimulation by milk protein fractions relies on the ambiguous nature of IL-6, which is necessary for the normal development of the nervous system but has neurotoxic and proconvulsive effects when increased levels are detected in the brain (Samland et al., 2003). The increase in IL-6 in the central nervous system after generalized seizure was more pronounced than the increase in plasma (Li et al., 2011). In general, the amount of IL-6 detected after stimulation of PBMC with milk and its fractions for all species was lower than that of other proinflammatory cytokines detected in this study, probably because this cytokine is not a reliable marker of epilepsy in the bloodstream. Indeed, 
Table 2. Effects of bulk milk and milk protein fractions of bovine, caprine, and ovine milk on cytokine levels (means $\pm \mathrm{SEM} ; \mathrm{pg} / \mathrm{mL}) \mathrm{in}$ cultured peripheral blood mononuclear cells of infants with generalized epilepsy

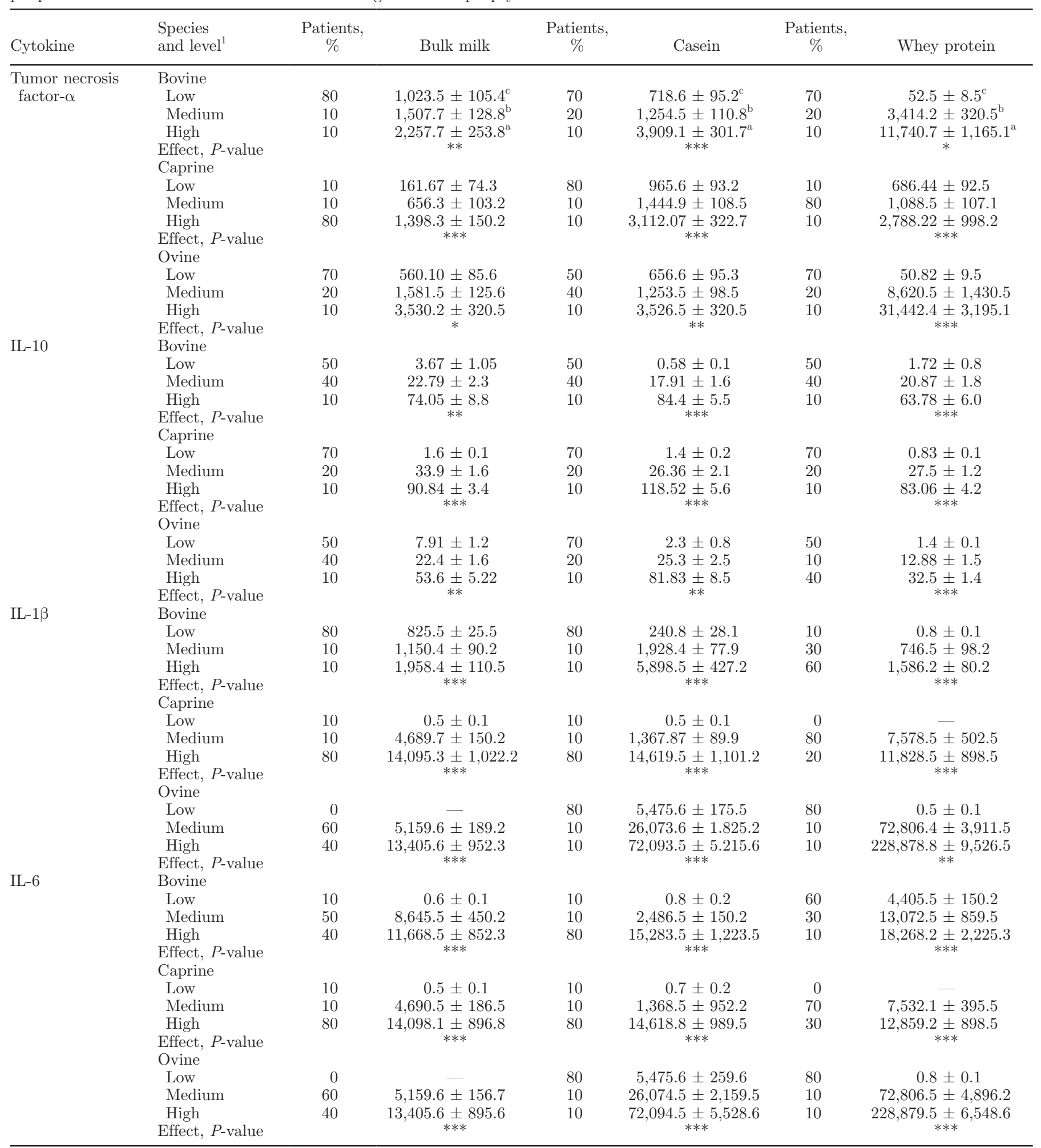

\footnotetext{
${ }^{\mathrm{a}-\mathrm{c}}$ Means with different superscripts differ $(P<0.05)$.

${ }^{1}$ The percentage of patients ascribed to each level is reported. The low, medium, and high levels grouped values that showed an increase $<30 \%$, between 30 and $70 \%$, and $>70 \%$ in respect to the threshold level, respectively.

${ }^{*} P<0.05 ;{ }^{* *} P<0.01 ;{ }^{* * *} P<0.001$.
} 


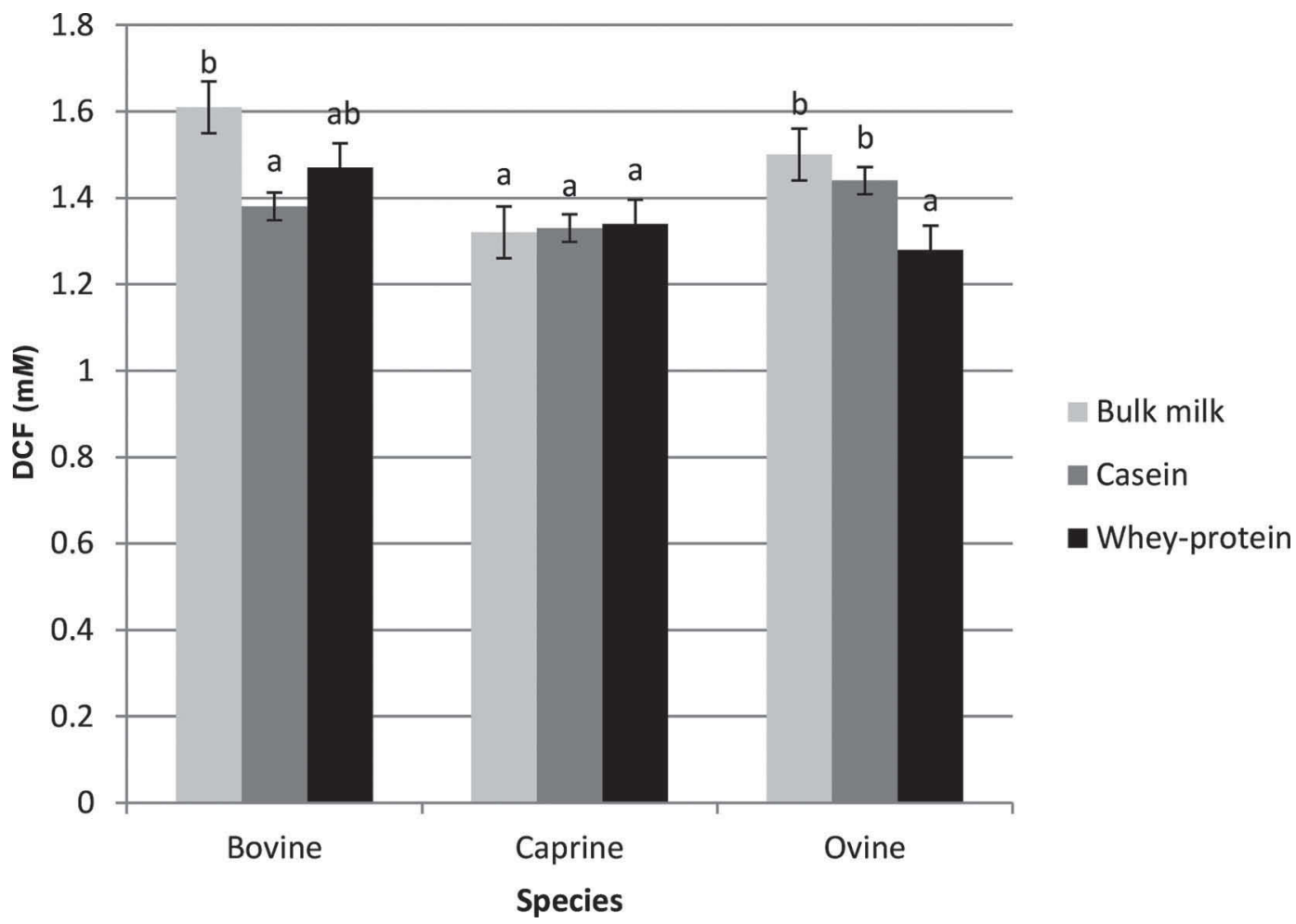

Figure 1. Effects of bulk milk and protein fractions from different species on reactive oxygen species and reactive nitrogen species (ROS/ RNS) levels in cultured peripheral blood mononuclear cells. Mean values with different letters (a, b) differ $(P<0.05)$; error bars indicate SEM. $\mathrm{DCF}=2^{\prime}, 7^{\prime}$-dichlorodihydrofluorescein.

Li et al. (2011) reported that the IL-6 level in plasma does not reliably reflect its level in brain.

Effects of stimulation of cultured PMBC with milk and protein fractions from different species on ROS/ RNS levels are presented in Figure 1. Levels of ROS/ RNS were higher in bovine and ovine milks than in caprine milk; within bovine milk, total free radicals were higher in bulk milk and lower in casein fraction whereas whey protein showed an intermediate level. In caprine milk, the ROS/RNS levels were not different among milk fractions; finally, ovine milk displayed higher levels for bulk milk and casein than for whey protein fraction. The increased levels of ROS are a direct indicator of elevated oxidative stress in biological systems; excessive production contributes to cell dysfunction and cell death (Hensley et al., 1995). The production of ROS is part of the killing strategy of effector cells within the $\mathrm{T}$ helper (Th) 1-type immune response, and it is also involved to further amplify the release of proinflammatory cytokines. An oxidizing milieu is also a trigger of the redox-sensitive signal transduction pathway in cells, including the induction of proinflammatory cytokines such as TNF- $\alpha$ (Murr et al., 2005). Lower levels of ROS/RNS detected in PBMC cultured with caprine milk fraction could be responsible for the lower levels of
TNF- $\alpha$ in the corresponding fraction. It was reported recently that oxidative damage occurring during epileptogenesis contributes to acute injury-induced neuronal damage leading to detrimental effects on areas of the brain associated with learning and memory function (Pearson et al., 2015). Those authors also suggested that the possibility of pairing antioxidants with antiseizure drugs, as a combination therapy, might help to reduce the cognitive impairment as comorbidities occurring in epileptic patients.

\section{CONCLUSIONS}

Production of cytokines and ROS/RNS by cultured PBMC from infants with generalized epilepsy was influenced by protein fractions of milk from bovine, caprine, and ovine species. The ability of PBMC to secrete cytokines in response to stimulation by milk and protein fractions may be a predictor of the secretion of pro- and antiinflammatory cytokines in the bloodstream of challenged patients. Detection of TNF- $\alpha$ and ROS/RNS in vitro may provide information on inflammatory status and oxidative damage occurring in infants with generalized epilepsy. Cytokines might be useful biomarkers to discriminate the effects of foods on the inflammatory 
response; dietary strategies could help in alleviating the negative effect of epilepsy in infants. Further investigations on milk components are needed to better clarify the mechanisms affecting immunological status in infant with generalized epilepsy.

\section{ACKNOWLEDGMENTS}

The present work was supported by Fondazione Cassa di Risparmio di Puglia, Bari, Italy. The research is part of the project titled "Focus on protein pattern in milk from different species: relationship between protein fractions and inflammatory response in human - Studio del profilo proteico del latte di specie diverse: relazioni tra le frazioni proteiche e la risposta infiammatoria nell'uomo."

\section{REFERENCES}

Albenzio, M., A. Campanozzi, M. D'Apolito, A. Santillo, M. Pettoello Mantovani, and A. Sevi. 2012. Differences in protein fraction from goat and cow milk and their role on cytokine production in children with cow's milk protein allergy. Small Rumin. Res. 105:202-205.

Albenzio, M., and A. Santillo. 2011. Biochemical characteristics of ewe and goat milk: Effect on the quality of dairy products. Small Rumin. Res. 101:33-40.

Asadi-Pooya, A. A., S. Mintzer, and M. R. Sperling. 2008. Nutritional supplements, foods, and epilepsy: Is there a relationship? Epilepsia 49:1819-1827.

Berg, A. T., S. F. Berkovic, M. J. Brodie, J. Buchhalter, J. H. Cross, W. van Emde Boas, J. Engel, J. French, T. A. Glauser, G. W. Mathern, S. L. Moshe', D. Nordli, P. Plouin, and E. Scheffer. 2010. Revised terminology and concepts for organization of seizures and epilepsies: Report of the ILAE Commission on Classification and Terminology, 2005-2009. Epilepsia 51:676-685.

Bernardino, L., S. Xapelli, A. P. Silva, B. Jakobsen, F. R. Poulsen, C. R. Oliveira, A. Vezzani, J. O. Malva, and J. Zimmer. 2005. Modulator effects of interleukin 1 beta and tumor necrosis factor-alpha on AMPA-induced excitotoxicity in mouse organotypic hippocampal slice cultures. J. Neurosci. 25:6734-6744.

Fox, P. F. 2003. Milk. Pages 1805-1812 in Encyclopedia of Dairy Sciences. H. Roginski, J. W. Fuquay, and P. F. Fox, ed. MPG Books Ltd., Bodmin, UK.

Gordon, K. E., and J. M. Dooley. 2015. Food insecurity and epilepsy in a nationally representative sample. Epilepsy Behav. 43:139-142.

Hensley, K., N. C. Hall, R. Subramaniam, P. Cole, M. Harris, M. Aksenov, M. Aksenovas, S. P. Gabbita, J. F. Wu, J. M. Carney, M. Lovell, W. R. Markesbery, and D. A. Butterfield. 1995. Brain regional correspondence between Alzheimer's disease histopathology and biomarkers of protein oxidation. J. Neurochem. 65:2146-2156.
IDF (International Dairy Federation). 1993. Determination of nitrogen content. Standard No. 20B. FIL-IDF, Brussels, Belgium.

Levin, S. G., and O. V. Godukhin. 2007. Protective effects of interleukin-10 on the development of epileptiform activity evoked by transient episodes of hypoxia in rat hippocampal slices. Neurosci. Behav. Physiol. 37:467-470.

Li, G., S. Bauer, M. Novak, B. Norwood, B. Rosenow, S. Knake, W. H. Oertel, and H. M. Hamer. 2011. Cytokines and epilepsy. Seizure 20:249-256

Michaelidou, A. M. 2008. Factors influencing nutritional and health profile of milk and milk products. Small Rumin. Res. 79:42-50.

Murr, C., K. Schroecksnadel, C. Winkler, M. Ledochowski, and D. Fushs. 2005. Antioxidants may increase the probability of developing allergic diseases and asthma. Med. Hypotheses 64:973-977.

Ng-Kwai-Hang, K. F., and F. Grosclaude. 2003. Genetic polymorphism of milk proteins. Pages 739-816 in Advanced Dairy Chemistry, Vol. 1, Part B, Proteins. 3rd ed. P. F. Fox and P. L. H. McSweeney, ed. Kluwer Academic/Plenum, New York, NY.

O'Garra, A., F. J. Barrat, A. G. Castro, A. Vicari, and C. Hawrylowicz. 2008. Strategies for use of IL-10 or its antagonists in human disease. Immunol. Rev. 223:114-131.

Pearson, J. N., S. Rowley, L. O. Liang, A. M. White, B. J. Day, and M. Patel. 2015. Reactive oxygen species mediate cognitive deficits in experimental temporal lobe epilepsy. Neurobiol. Dis. 82:289-297.

Plata-Salamán, C. R., S. E. Ilyin, N. P. Turrin, D. Gayle, M. C. Flynn, A. E. Romanovitch, M. E. Bureau, H. Anisman, and D. C. McIntyre. 2000. Kindling modulates the IL-1beta system, TNFalpha, TGF-beta1 and neuropeptide mRNAs in specific brain regions. Brain Res. Mol. Brain Res. 75:248-258.

Ravizza, T., and A. Vezzani. 2006. Status epilepticus induces timedependent and astrocytic expression of Il-1-receptor type-1 in the rat limbic system. Neuroscience 137:301-308.

Samland, H., S. Huitron-Resendiz, E. Masliah, J. Criado, S. J. Henriksen, and I. L. Campbell. 2003. Profound increase in sensitivity gluatamatergic but not cholinergic agonist induced seizyres in trans genic mice with astrocyte production of IL-6. J. Neurosci. Res. 73:176-187.

SAS Institute. 2011. SAS User's Guide: Statistics. Version 9.2 ed. SAS Inst. Inc., Cary, NC.

Shapiro, S. S., and M. Wilk. 1965. An analysis of variance test for normality. Biometrika 52:591-601.

Vezzani, A., S. Balosso, and T. Ravizza. 2008. The role of cytokines in the pathophysiology of epilepsy. Brain Behav. Immun. 22:797-803.

Vezzani, A., and T. Z. Baram. 2007. New roles for interleukin-1 $\beta$ in the mechanism of epilepsy. Epilepsy Curr. 7:45-50.

Virta, M., M. Hurme, and M. Helminen. 2002. Increased plasma levels of pro- and anti- inflammatory cytokines in patients with febrile seizures. Epilepsia 43:920-923.

Volpe, S. L., J. I. Schall, P. R. Gallagher, V. A. Stalling, and A. G. Bergqvist. 2007. Nutrient intakeof children with intractable epilepsy compared with healthy children. J. Am. Diet. Assoc. 107:1014-1018.

Youn, Y. 2013. The role of cytokines in seizures: Interleukin (IL)-1 $\beta$, IL-1Ra, IL-8, and IL-10. Korean J. Pediatr. 56:271-274.

Yuhas, Y., A. Weizman, and S. Ashkenazi. 2003. Bidirectional concentration-dependent effects of tumor necrosis factor-alpha in Shigella dysenteriae-related seizures. Infect. Immun. 71:2288-2291. 